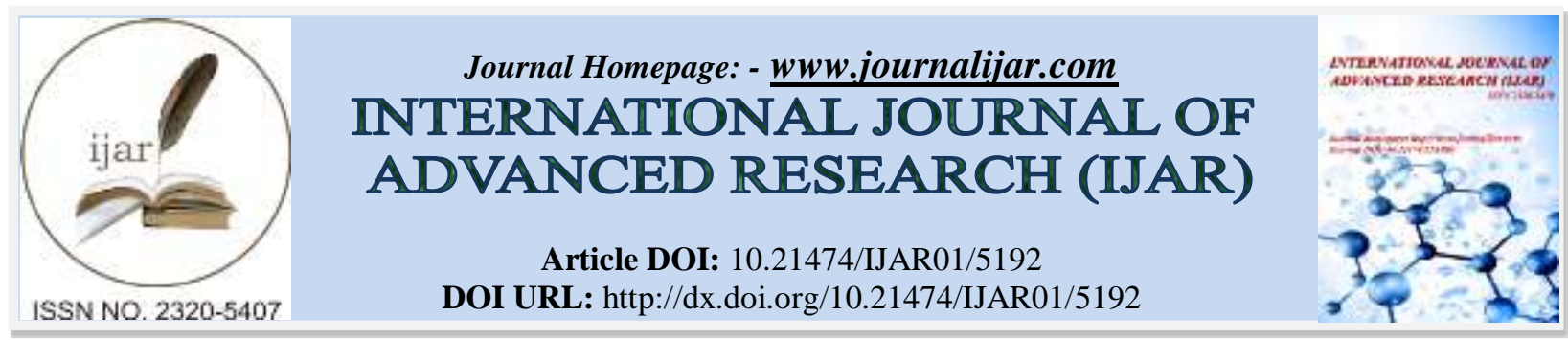

RESEARCH ARTICLE

\title{
COMPARISON OF SIDE EFFECTS LIKE PAIN ON INJECCTION AND MYOCLONUS DURING INDUCTION WITH ETOMIDATE AND THIOPENTONE IN CARDIAC SURGERY PATIENTS.
}

\section{Dr. Chanshetty Rajnish (Sr, Md Anaesthesia), Dr. Nimish Jain (Asst.Professor, Cardiac Anaeshtetist), Dr. Arun Kumar Haridas (Ctvs Surgeon) And Dr. Rama Upadhayaya (Professor\& Head). Department of Anaesthesiology, S.B.K.S. M.I. \& R.C., Sumandeep Vidhyapeeth, Piparia.}

\section{Manuscript Info}

Manuscript History

Received: 16 June 2017

Final Accepted: 18 July 2017

Published: August 2017

Key words:-

Ridge splitting, Expansion, Guided bone regeneration.

\begin{abstract}
Background: Several modifications have been applied to the ridge splitting with or without expansion technique to allow for implant placement in the atrophic ridges. Some studies utilized guided bone regeneration and others not. Aim: This systematic review will try to present the different studies discussing the effects of conjunction of bone grafting materials and/or membranes or not with the ridge splitting with or without expansion for patients having insufficient bucco-palatal ridge width. Methods: A thorough PUBMED (Medline) and COCHRANE databases search in addition to hand-search of journals of relevance was performed on related terms in the period from 1992 to 2016 and resulted in 3247 titles of which 21 abstracts were selected and collected as full articles for further evaluation while the rest were excluded by title or abstract. According to the inclusion criteria 14 studies were included and discussed in this article. Results: Of the 14 studies included in the present study only one study (cohortretrospective) compared ridge splitting with/without expansion technique alone and with guided bone regeneration. Twelve studies applied guided bone regeneration while three studies did not.
\end{abstract}

Copy Right, IJAR, 2017,. All rights reserved.

\section{Introduction:-}

The Induction of general anesthesia allowed Surgeons to operate with careful deliberation on patients made totally unaware and pain free.

With this arose the problem of inducing quick and reversible unconsciousness with minimal side effects. This was initially tried with inhalation agents and later intravenous agents.

The ideal intravenous induction agent would provide hypnosis, amnesia, analgesia, muscle relaxation without undesirable cardiac and respiratory depression and pleasantly induce anesthesia in one arm brain circulation time and completely wears off in a few minutes.

Thiopentone has been the routine induction agent of anesthesia since 1930's because of its rapid and predictable action. The main drawbacks are cardiovascular and respiratory depression, increased incidence of Laryngospasm, bronchospasm, allergic reactions. Thiopentone has survived the test of time as an intravenous anesthesia drug. 
The research for a better inducing agent which has good control of hemodynamic changes during intubation, The different agent like Etomidate have been tried with varied success.

The Etomidate was introduced into clinical practice in 1972. Its properties include hemodynamic stability, minimal respiratory depression, cerebral protection and rapid recovery after either a single dose or a continuous infusion. In practice these patients are compromised by trauma, serious illness, shock or cardiovascular co- morbidity. The fast onset of anesthesia and high therapeutic index for cardiovascular side effects are helpful during a rapid sequence induction.

Our study allows evaluation of Etomidate in comparison with Thiopentone sodium as an induction agent. This study aims an attempt to compare hemodynamic changes and other untoward effects of both the drugs.

\section{Aims And Objectives:-}

Among patients who come to a tertiary care hospital with select chronic disease (cardiovascular disease).

- $\quad$ To study hemodynamic changes after ETOMIDATE and THIOPENTONE usage.

- To study any complication arising as result of side effect of the etomidate and thiopentone if any

\section{Methodology:-}

Source and method of collection of data:-

An observational study of etomidate with thiopentone as an induction agent in cardiac surgery patients. After permission and clearence from the ethical committee ,this study was conducted in Dhiraj general hospital in Department of Anesthesiology. We did this study on 60 patients of Grade-I, II and III of American Society Of Anesthesiologist's (ASA) classification who were admitted for elective cardiac surgeries. The study was prospective in nature. All the patients participating in the study were explained clearly about the purpose and nature of the study in the language they can understand. They were included in the study only after obtaining a written informed consent. A cross sectional analysis was made at the time of presentation. We collected the data for 1.5 years and analyze the data statistically .

\section{Inclusion criteria:-}

Patients between the age group of 45 to 65 years of both sex belonging to American society of anesthesiology grade II to III undergoing elective cardiac surgery under general anesthesia.

- $\quad$ Adult patients posted for CABG

Patients were randomly divided into 2 groups of 30 each

a. Group E(30 patients) to be induced with inj.etomidate $0.3 \mathrm{mg} / \mathrm{kg} \mathrm{IV}$

b. Group T(30 patients) to be induced with inj. thiopentone $5 \mathrm{mg} / \mathrm{kg}$ IV

\section{Exclusion criteria:-}

- Patient refusal

- History of allergic reaction to the drug under study.

- Patients with renal and hepatic disease.

- Patients with history of epilepsy

- Carotid insufficiency.

- Adrenal insufficiency.

- $\quad$ ASA GRADE IV

- Presence of hypotension

- History of arrhythmia reoperative preparation:

Tab. Alprazolam $0.5 \mathrm{mg}$ were given on the night prior to surgery. Patients were asked to restrict fluids and solids by mouth at least eight hours before operation. The patients were reassured, the procedure of anesthesia explained and a written informed consent was obtained from them.

Patient were taken inside the operation theater .Oxygen was given by face mask. Intravenous line was secured with $16 \mathrm{G}$ or $18 \mathrm{G}$ cannula and the patients were given I.V.Fluids (NS) according to the requirement. Multipara monitors were attached and base line pulse rate, respiratory rate, non-invasive blood pressure, $\mathrm{SPO}_{2}$ and $\mathrm{ECG}$ were recorded. Under local anaesthesia a right radial artery is cannulated for invasive pressure monitoring and central venous line in right internal jugular vein for CVP monitoring was inserted. 
Patient were premedicated with inj.glycopyrrolate $0.2 \mathrm{mg}$,inj ondensatron $4 \mathrm{mg}$. Intravenous inj.fentanyl $5 \mathrm{mcg} / \mathrm{kg}$ was given over one minute before induction. Patients were randomized into two groups group $\mathrm{E}$ and group T, for patients receiving etomidate and thiopentone respectively. After preoxygenation with 100\% oxygen for 3-5 mins, Induction of anaesthesia was done either with etomidate $0.3 \mathrm{mg} / \mathrm{kg}$ or thiopentone $5 \mathrm{mg} / \mathrm{kg}$.. Loss of eye lash reflexes and lack of response to verbal commands was considered to be as end point of induction. Followed by this inj succinylcholine in doses of $1.5-2 \mathrm{mg} / \mathrm{kg}$ was given (depolarizing muscle relaxant) to facilitate tracheal intubation, patient was intubated after $1 \mathrm{~min}$ of interval.

After confirming the proper positon of endotracheal tube, it was connected to anaesthesia circuit. Patient was ventilated with 50\% oxygen and 50\% air along with inhalation agent and maintained with intravenous inj vecuronium. $0.1 \mathrm{mg} / \mathrm{kg}$

\section{Observation And Results:-}

Sixty patients of grade-II and III of American Society Of Anesthesiologists (ASA) classification were taken for study in elective cardiac surgeries. They were allocated randomly in two equal groups. (Group E - inj. Etomidate $0.3 \mathrm{mg} / \mathrm{kg}$ and Group T- inj.Thiopentone $5 \mathrm{mg} / \mathrm{kg}$ )

Demographic Data:-

Table 1:- Demographic Characteristics

\begin{tabular}{|l|l|l|l|}
\hline Variable & Group E & Group T & p-value \\
\hline Age (years) & $45.70 \pm 9.15$ & $47.60 \pm 9.27$ & 0.427 \\
\hline Weight $(\mathrm{kg})$ & $59.50 \pm 8.56$ & $60.70 \pm 9.27$ & 0.604 \\
\hline Sex $(\mathrm{M} / \mathrm{F})$ & $17(56.7 \%) / 13(43.3 \%)$ & $18(60 \%) / 12(40 \%)$ & 0.793 \\
\hline
\end{tabular}

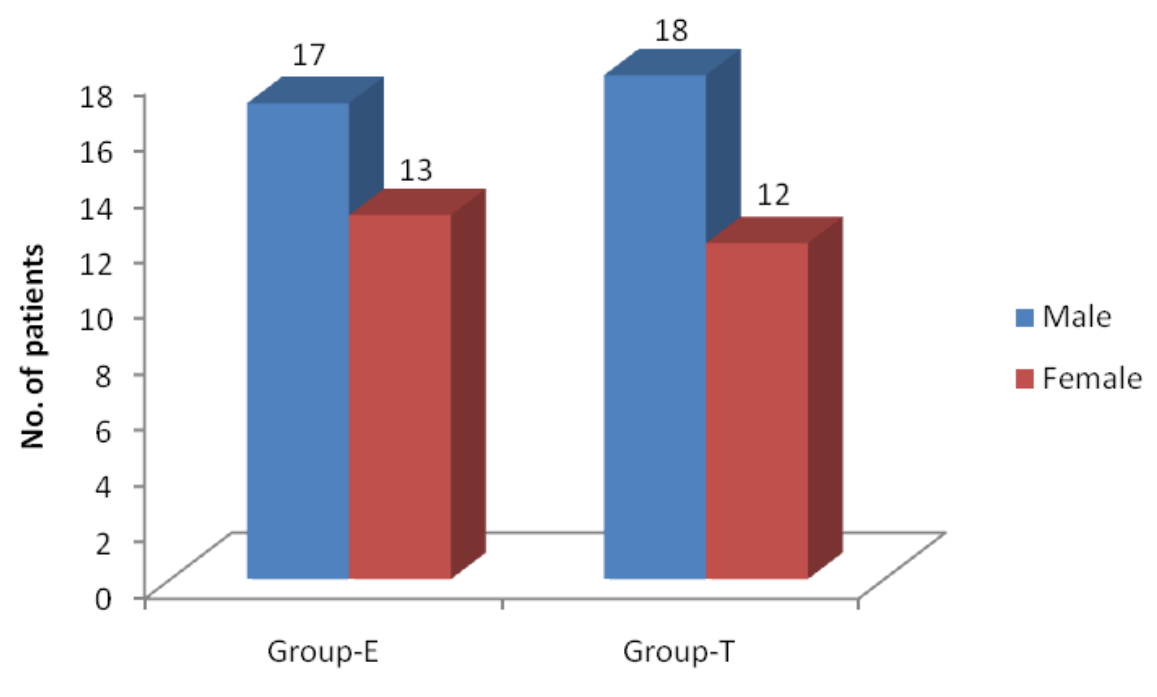

The distribution of patients with respect to sex were comparable in both groups.( p-0.793) 


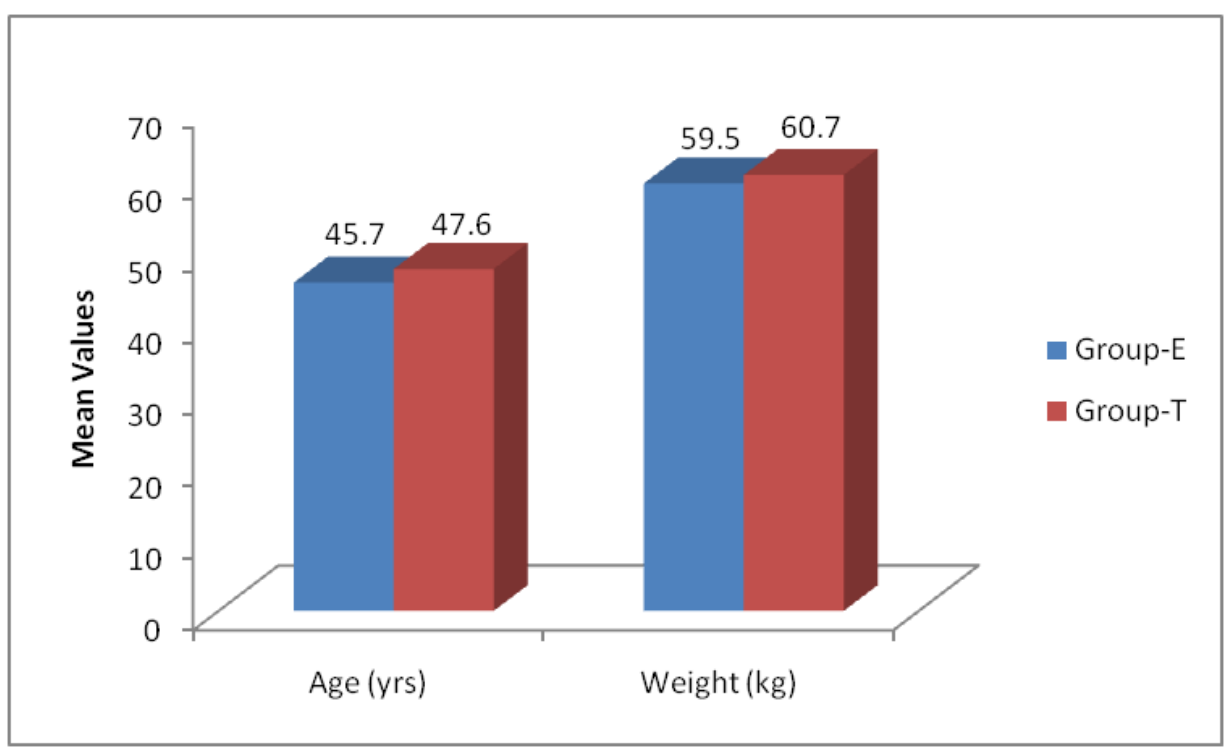

Fairly stable distribution of age confirms the hypothesis that the two groups were not different in the age. The mean Age in Group E was $45.70 \pm 9.15$ years while in Group $\mathrm{T}$ it was $47.60 \pm 9.268$ years which was statistically non significant $(\mathrm{p}>0.05$.

Fairly stable distribution of weight confirms the hypothesis that the two groups were not different in the weight.The mean weight in Group E was 59.50 \pm 8.561 years while in Group $\mathrm{T}$ it was $60.70 \pm 9.267$ years which was statistically non significant $(\mathrm{p}>0.05$.)

Pain on injectionin both group

\begin{tabular}{|l|l|l|l|}
\multirow{2}{*}{ Pain on Injection } & Group & Group-T & Total \\
\cline { 2 - 4 } & Group-E & $30(100 \%)$ & $40(66.7 \%)$ \\
\hline NIL & $15(50.0 \%)$ & $0(0 \%)$ & $20(33.3 \%)$ \\
\hline 1 & $15(50.0 \%)$ & $0(0 \%)$ & $0(0 \%)$ \\
\hline 2 & $0(0 \%)$ & $30(100 \%)$ & $60(100 \%)$ \\
\hline Total & $30(100 \%)$ & & \\
\hline
\end{tabular}

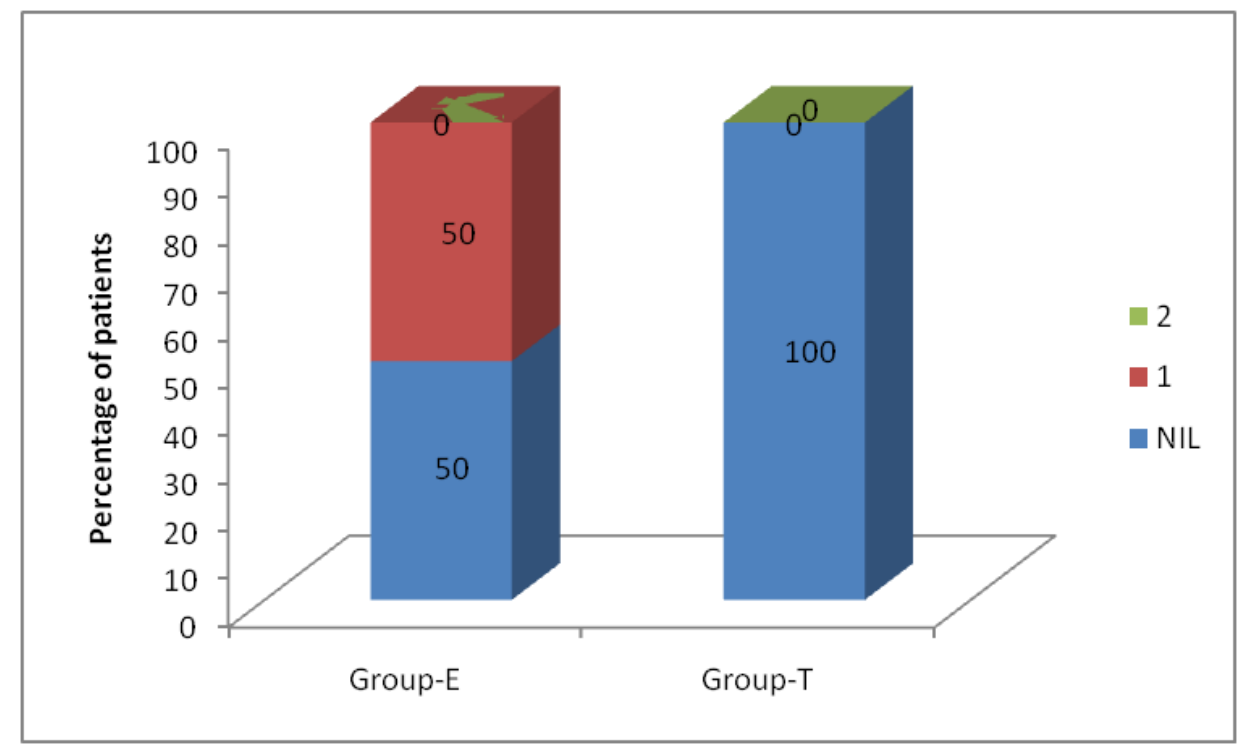


Pain on injection in the Group-E was observed in $50 \%$ patients, but none in Group-T. Which was statistically significant. $(\mathrm{p}<0.05)$

TABLE:- Myclonus in both the groups

\begin{tabular}{|l|l|l|l|} 
Myclonus & Group & Group-T & Total \\
& Group-E & $26(86.67 \%)$ & $43(71.67 \%)$ \\
NIL & $17(56.67 \%)$ & $4(13.33 \%)$ & $17(28.33 \%)$ \\
\hline Total & $13(43.33 \%)$ & 30 & 60 \\
\hline & 30 & $100.0 \%$ & $100.0 \%$ \\
\hline
\end{tabular}

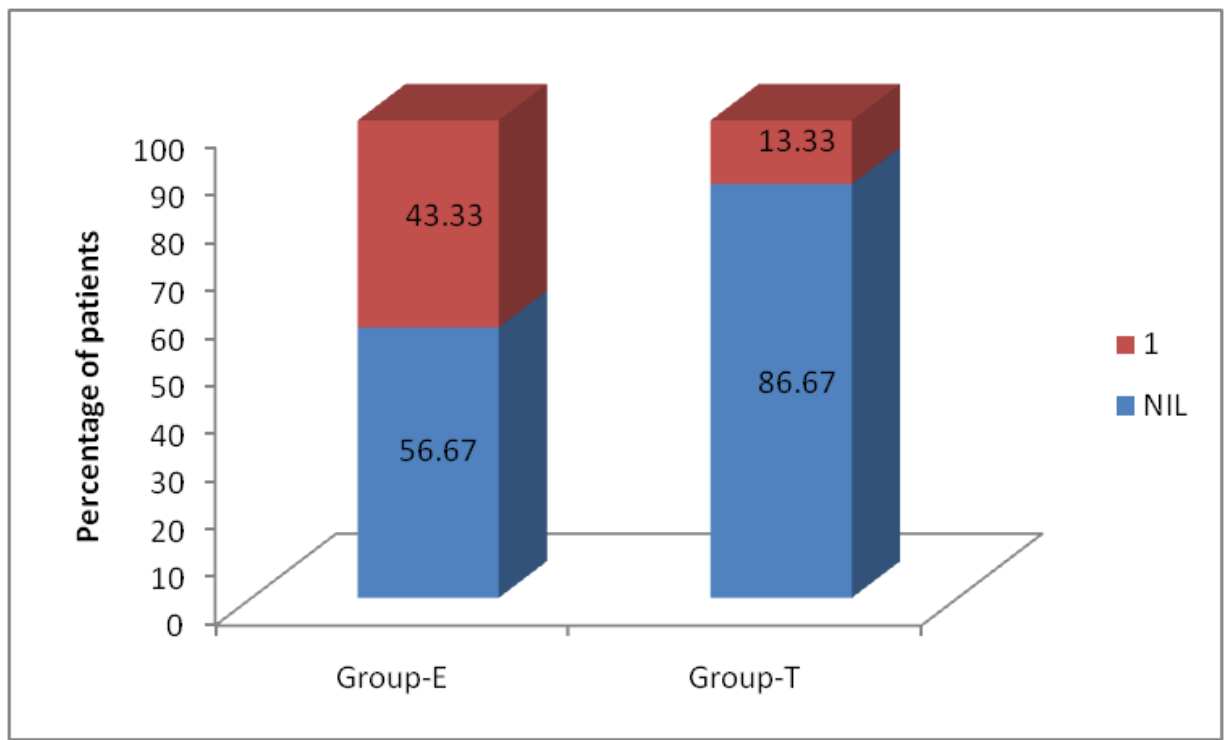

Incidence of side effect like myoclonus occurred in Group-E was $43 \%$ patients and in Group-T only $4 \%$ which was statistically significant.

\section{Discussion:-}

An ideal intravenous induction agent should produce minimal disturbance of cardiovascular and respiratory functions, should induce sleep in one arm brain circulation time, should chemically be stable, non inflammable, non toxic, easy to administer.

Etomidate has properties which suggest that it is a useful alternative to thiopentone with cardiovascular stability and with minimal respiratory depression.

Thiopentone has been the gold standard for induction agents since its introduction in to clinical practice by John Lundy in 1934. It is safe, reliable and is relatively in expensive.

There are however certain absolute contraindication for its use likes Barbiturate sensitivity and hereditary intetermittent porphyria. Due to its cardio respiratory depressive effects. Thiopentone is not the drug of choice in shocked patients or patients with associated cardio respiratory disease.

This study was undertaken to know the features of two drugs in elective cardiac surgeries when administered in a dose of Etomidate $0.3 \mathrm{mg} / \mathrm{kg}$ in comparison with inj Thiopentone $5 \mathrm{mg} / \mathrm{kg}$. The haemodynamic changes, time of loss of eye lash reflexes and study any complication arising as result of side effect of the etomidate and thiopentone if any.

Of these two drugs at Preinduction, at the time of induction, after intubation, three minutes after induction, five minutes after induction, seven minutes after induction and ten minutes after induction were observed. 
In our study a randomized clinical comparative evaluation of Inj Etomidate $0.3 \mathrm{mg} / \mathrm{kg}$ (group E) and inj thiopentone $5 \mathrm{mg} / \mathrm{kg}$ (group T) was done. 60 patients of ASA II-III undergoing elective cardiac surgeries participated in our study. The two groups were studied with respect to the age, sex and weight. pain on injecion, myoclonus, Induction time and hemodynamic parameters.

\section{Pain on injection:-}

In the present study the incidence of pain during injection was higher with Etomidate in 15 patients (50\%) and none in Thiopentone group. This correlates with reports by Batra ${ }^{45}$,et al., found that pain at the site of injection was noted in more number of cases of Etomidate (36\%).

Jefrey $^{42}$, et al., reported that the incidence of pain during iv Etomidate was higher than Thiopentone.

S V Korgaonkar found $20 \%$ of the patients complain pain after receiving inj Etomidate. This correlates with the incidence of 20\%-24\% reported by Gooding and corssen. Pain occurs most frequently from injections given in to small veins and in the wrist or back of the hand. The incidence of pain on injection was lesser if larger vein s like anticubital veins are used. And pain can be markedly reduced if injection is made faster. The Propylene Glycol may cause irritation and phlebitis can be minimized by administerd through a large vein with a rapid Intravenous infusion rate. ${ }^{(56)}$

Schou Olesen $\mathrm{A}^{62}$, et al., found that the pain on injection occurred in $24 \%$ of the patient receiving Etomidate

S W Chaudhary found that $14 \%$ of the patients complain of pain at the site of injection

Myoclonus: The incidence of myoclonus occurred in $43 \%$ of patients in Etomidate group and 13\% of patients in Thiopentone group in our study.

This is similar to reports by Batra ${ }^{45}$,et al. Incidence of myoclonus is $28 \%$ of patients of Etomidate group and none in Thiopentone group.

Jeffrey L Giese ,et al, found that patients in whom anesthesia was induced with Etomidate had myoclonus than Thiopentone. ${ }^{42}$

Desantos P, et al., also studied that the patients who were induced with Etomidate has higher incidence of occurrence of myoclonus. ${ }^{43}$

S W Choudhary ${ }^{64}$, et al., reported $18 \%$ of patients with Etomidate had involuntary muscle movements.

S C Shah ${ }^{65}$, et al., found that 18 patients had myoclonic movements.

V V Shah found the frequency of involuntary movements with Etomidate without premedication has been varied from 18\%-59\%.Incidence of involuntary movements in a form of myoclonia is very high. Frequency of involuntary movement's decreased significantly by various premedication drugs. ${ }^{67}$

\section{Summary:-}

The present study was conducted on 60 patients' age group between 45-65 years belonging to ASA grade II AND III. These patients were scheduled for elective cardiac surgeries.

Sixty patients were randomly selected, and divided in to two groups with thirty patients in each group. Group E patients were induced with Inj.Etomidate $0.3 \mathrm{mg} / \mathrm{kg}$ and Group $\mathrm{T}$ patients were induced with Inj Thiopentone $5 \mathrm{mg} / \mathrm{kg}$. as an induction agent.

The following parameters were compared between the group $\mathrm{E}$ and group $\mathrm{T}$, pain on injection, myoclonus, induction time and hemodynamic parameters.

Incidence of pain on injection is about $50 \%$ of the patients induced with Etomidate and absent in Thiopentone group. Myoclonus occurred in about $43 \%$ patients in etomidate group compared to 13\% patients in thiopentone group. 
Induction time was faster with Inj. Etomidate. which induced anesthesia at an average about $25 \pm 3.2$ seconds. Thiopental induced anesthesia at an average about $31 \pm 4.5$ seconds.

Hemodynamic changes with respect -to the _heart rate and blood pressure changes after premedication were minimal in both groups. At the time of induction there was minimal fall in blood pressure in Etomidate group but blood pressure significantly decreased in Thiopentone group.

After the intubation there were minimal changes in Etomidate group. heart rate and blood pressure were significantly raised in Thiopentone group.

To summarize both the groups shared complications like Pain on injection was present after inducing with Etomidate and it was absent in Thiopentone Myoclonus. It was more significant in Etomidate group than Thiopentone group.. The induction time was faster and smoother in Etomidate group, when compared with Thiopentone group. Etomidate has reduced cardiovascular response to laryngoscopy and tracheal intubation in comparison with Thiopentone in elective cardiac surgeries.

\section{Conclusion:-}

By the present study it can be concluded the induction time is lesser with Inj. Etomidate than Inj. Thiopentone. Etomidate is an effective and rapid acting induction anesthetic agent with good cardiovascular stability.

Finally, we conclude that Inj. Etomidate can be safe, hemodynamically stable and effective alternative to Inj.Thiopentone for the induction of general anesthesia in elective cardiac surgeries.

\section{Bibliography:-}

1. Lee AJ, S Atkinson, Rushman GB, NJH Davies. Lee's Synopsis of Anaesthesia. $11^{\text {th }}$ ed. ButterworthHeinemann international; 1993; 157-170

2. Stoelting RK, Simon MD, Hillier MB. Pharmacology and Physiology in Anesthetic practice. 4th ed. Lippincott Williams and Wilkins c ; 2006; 126-139,163-167

3. Thomas E J Healy and Paul R Knight, Andrew R A Rushton and Robert Sneyo Wylie and Churchill-Davidson's A Practice of Anesthesia Seventh Edition, chapter 35 clinical pharmacology and anesthetic techniques 2003; 572-577

4. Ronald D. Miller, J.G. Peter S, et al. Millers Anesthesia 6 Edition chapter 10 Intravenous non opioid anesthetic Elsevier Churchill Livingstone vol(1)s;317-355

5. Reich DL, Hossain S, Krol M, et al: Predictors of hypotension after induction of general anesthesia. Anesth Analg 101:622-628, 2005

6. Doenicke A, Gabanyi D, Lemce H, et al: [Haemodynamics and myocardial function after administration of three short-acting i.v. hypnotics, etomidate, propanidid, methohexital (author's transl)]. Anaesthesist 23:108-115, 1974

7. Hempelmann G, Piepenbrock S, Hempelmann W, et al: Influence of althesine and etomidate on blood gases (continuous PO2-monitoring) and hemodynamics in man. Acta Anaesthesiol Belg 25:402-412,1974

8. Rifat K, Gamulin Z, Gemperle M: [Etomidate: cardiovascular effects of a new intravenous anesthetic agent]. Can Anaesth Soc J 23:492-504, 1976

9. Creagh O, Torres H, Rodriguez N, et al: Alpha-2B adrenergic receptor mediated hemodynamic profile of etomidate. P R Health Sci J 29:91-95, 2010

10. Paris A, Philipp M, Tonner PH, et al: Activation of alpha 2Badrenoceptors mediates the cardiovascular effects of etomidate. Anesthesiology 99:889-895, 2003. 